\title{
BMJ Global Health Understanding factors impacting global priority of emergency care: a qualitative policy analysis
}

\author{
Portia I Chipendo, ${ }^{1}$ Yusra R Shawar, ${ }^{2}$ Jeremy Shiffman, ${ }^{2}$ Junaid Abdul Razzak ${ }^{3}$
}

To cite: Chipendo PI,

Shawar YR, Shiffman J, et al.

Understanding factors impacting

global priority of emergency

care: a qualitative policy

analysis. BMJ Global Health

2021;6:e006681. doi:10.1136/

bmjgh-2021-006681

Handling editor Stephanie M Topp

- Additional supplemental material is published online only. To view, please visit the journal online (http://dx.doi.org/10. 1136/bmjgh-2021-006681).

Received 21 June 2021 Accepted 25 November 2021

Check for updates

(c) Author(s) (or their employer(s)) 2021. Re-use permitted under CC BY-NC. No commercial re-use. See rights and permissions. Published by BMJ.

${ }^{1}$ Emergency Medicine, Johns Hopkins Medicine, Baltimore, Maryland, USA

2Department of International Health, Johns Hopkins Bloomberg School of Public Health, Baltimore, Maryland, USA

${ }^{3}$ Department of Emergency Medicine, Weill Cornell Medicine, New York, New York, USA

Correspondence to Dr Junaid Abdul Razzak; junaid.razzak@med.cornell.edu

\section{ABSTRACT}

Introduction The high burden of emergency medical conditions has not been met with adequate financial and political prioritisation especially in low and middle-income countries. We examined the factors that have shaped the priority of global emergency care and highlight potential responses by emergency care advocates.

Methods We conducted semistructured interviews with key experts in global emergency care practice, public health, health policy and advocacy. We then applied a policy framework based on political ethnography and content analysis to code for underlying themes.

Results We identified problem definition, coalition building, paucity of data and positioning, as the main challenges faced by emergency care advocates. Problem definition remains the key issue, with divergent ideas on what emergency care is, should be and what solutions are to be prioritised. Proponents have struggled to portray the urgency of the issue in a way that commands action from decision-makers. The lack of data further limits their effectiveness. However, there is much reason for optimism given the network's commitment to the issue, the emerging leadership and the existence of policy windows. Conclusion To improve global priority for emergency care, proponents should take advantage of the emerging governance structure and build consensus on definitions, generate data-driven solutions, find strategic framings and engage with non-traditional allies.

\section{INTRODUCTION \\ Background}

Emergency care is defined as the delivery of 'health services for conditions that require rapid intervention to avert death and disability, or for which delays of hours can worsen prognosis or render care less effective'. Emergency care is comprised of both prehospital and facility-based care. Prehospital care refers to medical services delivered within the community, at the scene and during transport, while facility-based care is delivered on arrival to a medical facility. An emergency care system (ECS) is how these services are organised and integrated into the broader health system. ${ }^{23}$ Because each health system

\section{Key questions}

What is already known?

- There is a high burden of emergency medical conditions globally.

- Emergency medical services do not receive much political or financial priority on the global health agenda.

\section{What are the new findings?}

The main challenges advocates face are:

- unclear definitions of the issues, proposed interventions and lack of supporting data.

- Lack of strong coalitions.

- Ineffective framing strategies.

\section{What do the new findings imply?}

Advocates could get more political and financial priority if they

- look internally to clearly define their issues.

- Look externally to build strategic coalitions and framing strategies

has its own unique gaps, the WHO developed an ECS framework that summaries the essential functions of an ECS and the essential resources needed. ${ }^{1}$

Robust ECSs are critical to addressing public health challenges and priorities. ${ }^{4}$ Globally, 24-28 million lives are lost annually due to conditions requiring emergency care, ${ }^{56}$ which accounts for $51 \%$ of mortality and $42 \%$ of all global disease burden. Additionally, the burden of emergency medical conditions is 4.4 times higher in low and middle-income countries (LMICs) compared with highincome countries (HICs). ${ }^{6}$

\section{Importance}

Despite its importance, delivery of quality emergency care in most LMICs remains challenging. ${ }^{7-9}$ Due to efforts by many stakeholders, there is growing incremental recognition of emergency care, resulting in World Health Assembly (WHA) resolutions that specifically highlight emergency care as an 
issue of global health priority. ${ }^{10-12}$ Nevertheless, there is still a large gap in attracting sufficient resources to advance the cause. ${ }^{13} 14$

While advocates for ECS development have a solid understanding of the need and the utility of their work, some have started to realise the challenges in gaining broader political priority. Many have highlighted challenges with quantifying the value of emergency care to external stakeholders, while others recognise the lost opportunities in linking ECS development to broader global health agendas. ${ }^{45}$ In most LMICs today, emergency care resembles what it looked like in HICs before the 1960 s. ${ }^{7}$ The delivery of emergency care is patchy and the quality is not standardised. The initial drive to improve emergency care in HICs was led by local grassroot movements from medical and surgical societies as well as growing public concern, leading to delineation of scope of practice and standardisation. ${ }^{710}$ This is not the case in LMICs, where there have been varied involvement of both local actors as well as advocates from HICs. Sriram et al describe the challenges faced by the local health systems when models of care developed in HICs, such as emergency medicine specialisation, are brought to LMICs. ${ }^{16}$

The emergency care literature has not placed sufficient attention towards understanding the factors that have limited political prioritisation of emergency care globally. Resources for global health are very limited, and it is paramount that these resources are allocated appropriately based on issue severity and need. Shiffman et al investigated some of the most successful global health networks such as the Maternal and New born survival proponents and found that their success was mainly driven by effective framing strategies and strategic coalitions. ${ }^{17}$ On the other hand, less-effective networks such as global surgery have faced similar challenges to emergency care. Shawar et alfound that fragmentation of ideas within the network, definitional issues as well as poor alignment with issues on the global health agenda such as Millennium Development Goals have limited the effectiveness of the global surgery community in attracting political priority. ${ }^{18}$

\section{Goals of the study}

We analyse the factors that have shaped political and financial prioritisation of emergency care at a global level. We specifically focus on the challenges and opportunities within the global emergency care community with the goal of stimulating deliberations among proponents on how to advance global priority for emergency care.

\section{METHODS}

\section{Study overview}

We used key informant interviews and reviewed literature to gather qualitative data on issues facing the global emergency care community. We then employed a policy framework to analyse themes emerging from the data.
Table 1 The four challenges that global health networks face $^{19}$

$\begin{array}{ll}\text { Problem definition } & \begin{array}{l}\text { Generating internal consensus on the } \\ \text { nature of the problem and solutions }\end{array} \\ \text { Positioning } & \begin{array}{l}\text { Portraying the issue in ways that inspire } \\ \text { the external audience to act }\end{array} \\ \text { Coalition building } & \begin{array}{l}\text { Forging alliances with external actors, } \\ \text { particularly ones outside the health } \\ \text { sector }\end{array} \\ \text { Governance } & \begin{array}{l}\text { Establishing institutions to facilitate } \\ \text { collective action }\end{array}\end{array}$

The study protocol was approved by the Johns Hopkins Institutional Review Board.

\section{Policy Framework}

Our analysis drew on the framework developed by Shiffman. ${ }^{19}$ The framework has been used to study global health networks including those focused on neonatal mortality, tobacco use, surgery and tuberculosis. The framework identifies four main challenges that global health networks face in attracting political and financial support for their causes, namely, (1) problem definition, (2) positioning, (3) coalition building and (4) governance (table 1$).{ }^{17} 19$

Problem definition refers to the internal framing of the issue within the network, reflected by how members of the network understand the problem and conceptualise the solutions. For instance, the global surgery network has faced problem definition challenges, given their divergent ideas on what the definition of surgical care is, which surgical interventions should be prioritised and who should be qualified to provide services. ${ }^{18}$

Positioning refers to how the issue is framed to attract external audiences. Networks use various strategies to attract the attention of well-resourced entities and political decision-makers. COVID-19, for instance, has emerged as a security issue as much as a public health issue. Similarly, maternal mortality gained prominence with a social justice positioning.

Coalition building pertains to the ability of a network to attract non-traditional allies. Effective networks look beyond the confines of their community to garner the attention of influential individuals who may not be directly involved in their cause. For example, Shawar et al found that the rheumatic heart disease (RHD) network faced challenges in garnering support because the network was physician-heavy and insular. ${ }^{20}$

Governance refers to how the network organises for collective action. Governance does not necessarily need to be hierarchical but can take many forms, including having a dominant lead organisation to having individual champions working together with equal decision-making power. $^{19}$ 
Table 2 Key informant affiliation and location classification by identification number

\begin{tabular}{|c|c|c|}
\hline $\begin{array}{l}\text { Key } \\
\text { informant }\end{array}$ & Primary affiliation & Location \\
\hline 1 & Academic Emergency Care & $\mathrm{HIC}$ \\
\hline 2 & Ministry of Health & LMIC \\
\hline 3 & Ministry of Health & LMIC \\
\hline 4 & Global Public Health & $\mathrm{HIC}$ \\
\hline 5 & Global Surgical Care & $\mathrm{HIC}$ \\
\hline 6 & $\begin{array}{l}\text { Global Public Health and Pediatric } \\
\text { Care }\end{array}$ & LMIC \\
\hline 7 & Regional Professional Society & LMIC \\
\hline 8 & UN agency & LMIC \\
\hline 9 & Academic Emergency Care & LMIC \\
\hline 10 & National Professional Society & $\mathrm{HIC}$ \\
\hline 11 & Academic Emergency Gare & $\mathrm{HIC}$ \\
\hline 12 & International Disaster Expert & $\mathrm{HIC}$ \\
\hline 13 & Academic Emergency Care & $\mathrm{HIC}$ \\
\hline 14 & Global Public Health & LMIC \\
\hline 15 & International Professional Society & $\mathrm{HIC}$ \\
\hline 16 & Regional Professional Society & LMIC \\
\hline 17 & International Funding Agency & $\mathrm{HIC}$ \\
\hline 18 & Academic Emergency Care & $\mathrm{HIC}$ \\
\hline 19 & Academic Emergency Care & $\mathrm{HIC}$ \\
\hline 20 & Global Public Health & $\mathrm{HIC}$ \\
\hline 21 & United States Federal agency & $\mathrm{HIC}$ \\
\hline 22 & Global Public Health & $\mathrm{HIC}$ \\
\hline 23 & Global Public Health & $\mathrm{HIC}$ \\
\hline 24 & UN Agency & $\mathrm{HIC}$ \\
\hline 25 & Global Research Agency & LMIC \\
\hline
\end{tabular}

HIC, high-income country; LMIC, low and middle-income country.

\section{Study setting}

This study was performed in the USA, however, key informants from various regions of the world were interviewed via telephone and online platforms.

\section{Selection of participants}

We recruited participants between 1 August 2019 and 1 May 2020 using a standardised email. All participants were proficient in English and provided written consent. Participant selection was initially purposive in that we preselected experts who are known leaders in global emergency care advocacy and other relevant areas of global public health. They included clinicians, public health practitioners, researchers and policymakers (tables 2 and $3)$. The focus was on actors with experience at the global level, but we also included some individuals working at the regional and national levels. Global, regional and national delineation was based on the primary mandate of the organisation represented by the individual participant. We then employed snowball sampling to identify
Table 3 Key informant characteristics

\begin{tabular}{|c|c|c|}
\hline & & Frequency \\
\hline \multirow[t]{2}{*}{ Income level } & $\mathrm{HIC}$ & 16 \\
\hline & LMIC & 9 \\
\hline \multirow[t]{2}{*}{ Gender } & Male & 18 \\
\hline & Female & 7 \\
\hline \multirow[t]{20}{*}{ Institutions } & WHO & 2 \\
\hline & Bloomberg Foundation & 1 \\
\hline & Johns Hopkins University & 4 \\
\hline & $\begin{array}{l}\text { United States Centers for } \\
\text { Disease Control and Prevention }\end{array}$ & 2 \\
\hline & $\begin{array}{l}\text { George Institute for Global } \\
\text { Health }\end{array}$ & 1 \\
\hline & $\begin{array}{l}\text { International Federation for } \\
\text { Emergency Medicine }\end{array}$ & 1 \\
\hline & $\begin{array}{l}\text { African Federation for } \\
\text { Emergency Medicine }\end{array}$ & 3 \\
\hline & University of Colorado & 1 \\
\hline & Ministry of Health Malawi & 1 \\
\hline & Ministry of Health South Africa & 1 \\
\hline & University of Cape town & 2 \\
\hline & Aga Khan University East Africa & 2 \\
\hline & University of Washington & 1 \\
\hline & Uniformed Services University & 1 \\
\hline & Brown University & 1 \\
\hline & University of Chicago & 1 \\
\hline & $\begin{array}{l}\text { Seoul National University } \\
\text { College of Medicine }\end{array}$ & 1 \\
\hline & Leeds Teaching Hospitals & 1 \\
\hline & Emory University & 1 \\
\hline & George Washington University & 1 \\
\hline
\end{tabular}

HIC, high-income country; LMIC, low and middle-income country.

additional participants. By the 25th interview, we had reached theoretical saturation, the point at which no new information was obtained.

\section{Data collection}

We used mostly open-ended questions to conduct interviews through telephone and online Platforms (please see online supplemental material for sample questions). Each interview lasted an average of 1 hour, and field notes were obtained during the interviews. We did not pilot test the interview guide, and there were no repeat interviews. The interviews were recorded, deidentified and transcribed by a professional transcription service. The transcripts were not returned to participants.

Dr Chipendo MD.MPP conducted the interviews, coded and analysed the data. At that time, she was in her fourth year of emergency medicine residency training, with a special focus on global health and policy. Dr Yusra, Shawar, Ph.D, an expert in qualitative research, global 


\begin{tabular}{|c|c|c|}
\hline & Global emergency care challenges & Global emergency care opportunities \\
\hline $\begin{array}{l}\text { Problem } \\
\text { definition }\end{array}$ & $\begin{array}{l}\text { No clear consensus on definitions and scope of } \\
\text { emergency care } \\
\text { Lack of emergency care data on epidemiology, } \\
\text { resources, interventions, outcomes in LMICs } \\
\text { Lack of clarity between advocacy for emergency } \\
\text { medicine specialisation and emergency care } \\
\text { development }\end{array}$ & $\begin{array}{l}\text { Emerging tools and frameworks coming from WHO } \\
\text { Consensus on the need for more data from LMICs } \\
\text { Increased representation from LMICs }\end{array}$ \\
\hline Positioning & $\begin{array}{l}\text { Lack of clear demands } \\
\text { Lack of credible supporting data } \\
\text { Lack of strategies to engage emotionally with the } \\
\text { audience } \\
\text { Lack of experience and skills in advocacy among } \\
\text { actors }\end{array}$ & $\begin{array}{l}\text { A consensus within the network that there is a need for } \\
\text { more strategic framing } \\
\text { A growing literature on several potentially effective } \\
\text { framing strategies } \\
\text { Opportunities to engage with non-traditional allies for } \\
\text { collective messaging } \\
\text { Policy windows created by WHA resolutions, } \\
\text { humanitarian emergencies, and disasters }\end{array}$ \\
\hline Coalitions & $\begin{array}{l}\text { Lack of engagement with grassroots organisations } \\
\text { Poor representation and visibility of non-emergency } \\
\text { medicine actors } \\
\text { Limited engagement with local policy agendas }\end{array}$ & $\begin{array}{l}\text { Collaborations with vertical programmes } \\
\text { Collaborations with local leaders }\end{array}$ \\
\hline Governance & $\begin{array}{l}\text { Lack of a clear global governing body } \\
\text { Fragmented network } \\
\text { The unequal platform between actors from HICs and } \\
\text { those from LMICs }\end{array}$ & $\begin{array}{l}\text { Desire for centralisation } \\
\text { Growing linkages among actors and organisations } \\
\text { Growing representation and formation of regional and } \\
\text { national organisations }\end{array}$ \\
\hline
\end{tabular}

HICs, high-income countries; LMICs, low and middle-income countries.

health and politics participated as a cofacilitator in some of the interviews. Both researchers had no prior personal relationships with the participants.

\section{Data analysis}

We used expert opinions from in-depth interviews to identify underlying elements of causality and power. ${ }^{21}$ We undertook a thematic analysis of the collected information using an iterative process in developing codes. We originally coded by broad categories derived from policy frameworks that examine the determinants of political priority for global health issues. ${ }^{17} 19$ These categories were issue characteristics, policy environment and network and actor features. ${ }^{17} 19$ The coding evolved to also include problem definition, positioning, coalition building and governance. Subthemes from these broad categories included data inadequacy, complexity of problems and interventions as well as balance of power among actors (table 4). We triangulated data sources including interviews, literature review, organisational documents to minimise bias and validate the findings. We adhered to the Consolidated Criteria for Reporting Qualitative Research (COREQ) reporting guidelines for our data analysis. ${ }^{22}$ We used a single coder, and the data were analysed in Microsoft Word.

\section{Literature review}

The literature review was aimed at validating and augmenting data from the interviews. The literature review was performed concurrently with the interviews. We searched for information on the current state of emergency care efforts in LMICs looking at challenges, proposed interventions and network organisation. We searched PubMed and the Global Health databases for articles written in English between 1990 and 2020. We found a total of 1071 unique articles and reviewed all abstracts for relevance. Of those articles, 47 were found to be relevant. Additionally, we browsed relevant topics on organisational websites concerned with emergency care, used Google Scholar and also reviewed specific articles referenced by our key informants. This was not a systematic literature review. Articles were selected based on their relevance to global emergency care development.

\section{Patient and public involvement}

The research question and outcome of the study were not directly related to the patients' priorities, experience and preferences. Patients were not involved in the design, recruitment or conduct of the study. We will disseminate our results through scientific publication, conference presentations as well as through social media.

\section{RESULTS}

\section{Characteristics of the key informants}

We contacted 42 experts through a standardised email. In total, 35 responded, 3 declined to be interviewed and 7 had difficulties with scheduling. In terms of the geographical distribution, $64 \%$ were based in HICs and $36 \%$ from LMICs. This skew is because most of the visible actors driving emergency care advocacy at the global level are located in HICs. A broad range of organisations and 
areas of expertise were represented as shown in tables 2 and 3 .

\section{MAIN RESULTS \\ Problem definition}

Core concepts of emergency care

The emergency care community broadly agrees on what constitutes a medical emergency, sometimes referred to as a 'true emergency'. ${ }^{12}$ Most highlight the acuity of the condition, the need for specific time-sensitive interventions to prevent morbidity or mortality (interviews 1,2 , $6,11,12,22,24)$. However, the scope of emergency care outside of these 'true medical emergencies' is an area of ongoing debate. Proponents for the specialty of emergency medicine highlight the need for a defined scope of practice that commands respect from peer specialties:

...when you define emergency medicine, you don't define just what it is. You also define what it is not, and nobody takes the steps to define what it is not (interview 16).

These experts argue that incorporating service areas such as public health and preventative care compromises the prestige of the specialty. However, some argue that emergency medical care should evolve to fill whatever gaps exist in the health system:

...we would be doing a disservice to the field if we think of emergency care only as the true emergencies because again, in terms of access, that is the only option for a lot of patients (interview 21).

Some key informants believe that emergency care is a set of building blocks that a health system arranges to match their healthcare needs (interviews $3,9,15,24){ }^{7}$ But,

...there is still no agreement on what people define as the core or the essentials of emergency care (interview 24). ${ }^{2324}$

A minority of experts within the community define emergency care as the failure of an ideal healthcare system; hence, they argue that it should not be disseminated to LMICs.

...it would be more cost-effective if we concentrated on prevention activities which are less expensive then, in theory, if it's done well, it would avoid the amount of people that need emergency care (interview 22).

However, most experts agree that despite investments in primary care, people will continue to have heart attacks, strokes and road traffic accidents; hence, emergency care development remains necessary. ${ }^{25} 26$

The language around emergency care and emergency medicine has been confusing (interviews 6, 15). Emergency medicine is a recognised specialty in many HICs. It is primarily hospital-based and has a focus on residency training. Emergency care, on the other hand, is care delivered to a patient with an emergency irrespective of where they are and who is treating them. Some within the community have used these words interchangeably, leading to misunderstandings. One expert from LMIC highlighted this:

...when some emergency medicine practitioners from HICs talk about emergency care in LMICs they are seeing it very much from the lens of emergency medicine (interview 15).

Even at high levels within the network, definitions have been a challenge:

...IFEM [International Federation of Emergency Medicine] is struggling because ...it's got all of the high-income countries saying we have emergency medicine problems ... and then all of its new members are low-income [countries] saying we have emergency care problems that need solving (interview 7).

Finally, at the level of the WHO, the term emergency is traditionally used for disasters. There is fragmentation on where different aspects of emergency care are housed, including violence and injury, patient safety and emergency surgery, further adding to the confusion. ${ }^{14}$

\section{Proposed interventions}

The literature review identified many proposed interventions such as organising prehospital systems, acuitybased triage, standardised protocols and training. Others advocate for a single call number, residency training and first responder training. ${ }^{14}{ }^{27-29}$ However, there is disagreement within the community on which strategies to prioritise, primarily due to lack of supporting data. ${ }^{14}$ The community agrees that more research is needed (interviews $6,16,17) .{ }^{36}$ Some believe that implementing interventions should wait until proven effective (interviews 6 , 17,20 ), while others (interviews 1, 9, 16, 19) argue that:

...the enemy of good is better.... is there enough data from those countries? No... But there's enough data to make a start (interview 16).

In most LMICs, facility-based emergency care is delivered by providers from multiple specialties, usually trainees or those who are in-between careers. The emergency care community is divided into those who promote basic training of non-emergency medicine specialists and those who advocate for specialist training (interviews 6 , 15). However, credible data on which model works better in LMICs are lacking. ${ }^{30}$ Some, especially those from LMICs, argue that focusing on specialist training early in ECS development is a double standard, as the specialty of emergency medicine evolved naturally in HICs (interview 6$)$.

\section{Positioning}

The emergency care community has struggled to attract political elites and multilateral funders who control resources for global health initiatives. The network has used various approaches to engage these stakeholders. Some have argued that emergency care is a critical component of the healthcare system paramount to achieving multiple targets on the global health agendas such the 
Sustainable Development Goals and Universal Health coverage (interviews 8,11$).{ }^{347}$ Others have argued that emergency care provides access to the healthcare system, especially for vulnerable populations, hence, should be viewed as a human right ${ }^{31} 32$ (interview 7). Key informants identified the main challenges in positioning (interviews $1,7,8,11,17,20,25)$ as summarised by one expert:

\begin{abstract}
...we have a public image problem: who are we; who is it we're trying to engage; what are we trying to sell; and who are we trying to sell it to? We don't really know because it's so wide, it's everybody and nobody. And no one thinks about it until it affects them (interview 7).
\end{abstract}

To clarify the issues to stakeholders, the WHO developed the ECS Framework, which defines essential components of an ECS. ${ }^{1}$ This tool has started to gain some traction but is not yet well disseminated (interviews $1,3,9)$. Currently, global emergency care is driven mostly by academic clinicians who neither have the time nor experience in messaging (interview 8, 20). Some nonclinical experts suggested that having clinicians be the predominant voice has led to a misconception that the community is lobbying for the specialty of emergency medicine and not necessarily for patients and the healthcare system (interviews $1,8,10,11,20,24$ ).

They see an emergency medicine doctor advocating for attention, they just saw the general surgeon doing it for hernia care, the eye doctors doing it for cataracts, and the plastic surgeon doing it for cleft lips.... there is this whole parade of people and Emergency care is just another one in that long line. That is not the truth, but it's our fault because we framed it that way... (interview 11).

Some raised the issue that the models of emergency care developed and disseminated from HICs are seen as the 'gold standard' and go unquestioned. As a result, decision-makers are left with the perception that emergency care is a resource intensive, highly specialised clinical field that is too costly to pursue. As one expert explained,

One of the struggles in medicine is that we have set a gold standard for many things, even in research, we say that an intervention is effective if it has been studied under this context and anything else is not acceptable ... (interview 24).

This view has limited the community from exploring possible alternative models of care specific to LMICs (interview 24). The lack of specific data to quantify the problem and support proposed interventions in LMICs has limited the effectiveness of the proponents to engage funders and decision-makers. ${ }^{3}$

Once we have solid evidence, we need to package it properly, and make sure the policymakers understand the need and the return on investments...., then we have to communicate that as one voice. We've got to set up a set of interventions and make sure that countries who are ... doing it well, help us make the case to those countries that are not doing it well (interview 20).
There is consensus that there were lost opportunities to make a case for emergency care during disasters and disease outbreaks such as Ebola (interview 7, 19, 22). Several informants pointed out that those events were policy windows, where an organised emergency care network could have advocated for building capacity (interviews 1, 7, 19).

\section{Governance}

The emergency care network has looked up to WHO as a politically neutral global health leader with convening powers and a well-respected reputation among academics, governments and large donors (Interviews 1,4, 7, 8, 19). Most informants identified the Emergency, Trauma and Acute care programme at WHO as the most influential leader in driving global emergency care (interviews 1, 2, $3,7,9,22,24,25)$. This office is separate from the WHO Health Emergencies Programme, which mainly deals with humanitarian emergencies. Leadership through the WHO has resulted in the recent production of some tools to address issues with emergency care, such as the WHO infographic, health systems assessment tools, triage tools and the Basic Emergency Care course. ${ }^{1}$ Additionally, the WHO has shown leadership by providing a convening platform that has raised emergency care on the global agenda through the WHA resolutions ((WHA60.22 (2007), WHA68.15 (2015) and WHA72.16 (2019))..$^{10-12}$

Despite these achievements, some argue that the organisation has not made itself a clear and visible leader that commands collective action (interviews 2, 3, 20, 24, 25). For instance, when asked to identify the leading institution for global emergency care one expert responded:

I guess, it should be the WHO. You know, they are the global public health agency. It should be WHO, but is it? I'm not sure (interview 25).

Governance through the WHO was described as fragmented partly due to the horizontal nature and broad scope of emergency care. One informant highlighted:

WHO is split, its emergency care people are in different departments all the time. So, I don't know if there is a single voice where we can find an organization that promotes emergency care (interview 20).

Some even suggested that the fragmentation within WHO has distorted emergency care in LMICs as many countries look up to the WHO structure as a model for their health systems (interview 25).

...WHO doesn't realize that many Ministries of Health in low- and middle-income countries mimic what WHO does as far as stratification or division of issues... And so, if there's fragmentation at WHO, that tends to ripple down to Ministries of Health and is then mimicked at a national level (interview 25).

Faculty members from academic institutions in HICs are often identified as leaders in educational programmes and emergency care research in LMICs (1, $8,19)$. These academics usually work in partnership with 
local universities, hospitals and sometimes ministries of health. ${ }^{33-35}$ Leadership through academia has been hindered by mistrust by local stakeholders and lack of collaboration among actors. ${ }^{25}$ As one expert summarised:

Academics can collaborate but only to a certain extent and at the end of the day, their pay checks and their ability to tie down their critical time comes from their ability to get grants (interview 11).

According to some experts, there is some inherent ignorance among some actors who give more weight to technical expertise and dismiss the significance of local knowledge (interviews 1, 2, 10, 14, 24):

There is less exchange, real exchange, and there is an expectation that there is this transfer of knowledge from a high-income or developed setting to the local settings (interview 24).

This has led to a poor understanding of local priorities, redundancies and unsustainable initiatives. ${ }^{35-37}$ Despite these limitations, academia remains a core strength of the governance structure of the global emergency care network (interview 1).

Organisations such as International Federation of Emergency Medicine (IFEM), African Federation of Emergency Medicine and American College of Emergency Physicians have more recently emerged as rising leaders in global emergency care. These are international, regional and national organisations, respectively. IFEM convened task forces and committees of international health professionals to develop international curricula for emergency physician training. ${ }^{1038}$ Although the traditional mandate for emergency medicine specialty organisations in HICs is on advancing political prioritisation of the specialty at a national level, there have been some efforts to broaden their scope to promote emergency care in LMICs. However, there is less of an expectation for these HIC emergency medicine-focused groups to be the central leaders in global emergency care as it pertains to LMICs. As one informant noted:

ACEP is basically a union. It's a huge political machine that lobbies at a federal level and its only interest is revenue share for its members. Because that's what it should be. That's what it's always been right from the start... That's not a criticism. The problem is: most other countries don't have an ACEP (interview 16).

\section{Coalitions}

The emergency care network has been internally focused and has not made significant collaborations with non-traditional allies such as well-funded vertical programmes, community groups and philanthropic organisations. ${ }^{14}$ Because emergency care cuts across so many disease areas, there are potential gains in collaborating with traditional programmes such as HIV/AIDs, maternal and neonatal health (interviews 5, 6, 9). One expert noted how emergency care should take advantage of its horizontal nature and learn from other disciplines that encompass diverse groups of people:

For example, new-born medicine requires pediatricians, obstetricians, mid-wives, nurses.... Although success has varied, generally, they've been able to align things together, and speak with a consistent single voice (interview 5).

There is consensus among key informants that the network has not had effective coalitions with grassroots organisations (interviews 24, 25). Local non-governmental organisations, unions and victims' organisations can help with designing and implementing context-specific solutions as well as providing local narratives for advocacy. ${ }^{23} 25$ 39-42 One expert highlighted this:

When they [community organizations] are armed with correct information, they are very good at sharing that information and advocating for policy change.... we use statistics. We use numbers. They use people. They use loved ones (interview 25).

We used purposive and snow-balling techniques to recruit participants and, hence, we might have missed certain stakeholders or over represented particular groups. In our design, we attempted to get a broad perspective on emergency care representing views of emergency care practitioners as well as those who are not involved in emergency care routinely. We also ensured participation from HIC and LMICs, policymakers, clinicians and public health leaders. The selected coding categories may have left some themes unexplored. However, the major categories were selected based on strong qualitative literature frameworks used in similar studies on global health networks. ${ }^{17-20}$ Our analysis was set in prior to COVID-19 pandemic. We believe that the pandemic will have significant impact on national and global focus on emergency care and raise different types of issues not captured in this analysis.

\section{DISCUSSION}

Our analysis identified several challenges to advance political support for emergency care (table 4). Problem definition is a key issue with lack of clarity and consensus on the definition and scope of emergency care and sometimes competing advocacy for emergency medicine as a specialty and emergency care as a health system intervention. Like other issues with a horizontal nature such as global surgery, the broad scope makes it challenging to find internal coherence within the network. ${ }^{18}$ Additionally, the global health arena is used to disease-focused initiatives and other vertical programmes; hence, it becomes a significant challenge to get attention on a broad issue such as emergency care.

Similarly, the positioning of emergency care suffers from vague framing of the issue and lack of clear and effective interventions to improve emergency care. The fact that the community is mainly composed of emergency medicine clinicians with limited experience and skills in advocacy and marketing further hamper global 
positioning. The network needs to find framings that create an understanding of threat, urgency, severity, costeffectiveness of investment and generate an ethical imperative for action among decision-makers and funders. Proponents for early childhood development (ECD) face similar challenges given that ECD remains a nebulous concept, compounded by cross-national differences in ECD challenges, weak data availability and monitoring mechanisms and a misperception in some countries that there are no immediate payoffs to investment in ECD, making the issue less politically attractive. ${ }^{43}$

There is a coalition between HIC and LMIC practitioners and academics under various emergency medicine organisations, yet the perception of the usefulness of that coalition remains variable. Importantly, the coalition remains largely confined to emergency medicine practitioners and has not been able to attract grassroot organisations or non-emergency medicine healthcare groups. These interconnected factors explain why emergency care is struggling to attract necessary political support and resources. This is a similar challenge facing proponents concerned with RHD, who are largely clinicians and most of whom are specialists; there is little engagement with advocates from other health and development communities, or those directly affected by RHD. ${ }^{20}$

Despite these challenges, there are good reasons for optimism. The emergency medicine community is driven to improve emergency care globally. There has been ongoing work on problem definition led by WHO, Fogarty International Centre at NIH and others. ${ }^{12}$ There is growing understanding of the impact of emergency care on the burden of diseases and potential economic benefits. There are measures of disparities emerging between HIC and LMICs. WHO, IFEM and other emergency medicine specialty societies have created a coalition with greater engagement of regional and national organisations and there are centres of excellence on emergency medicine supporting emergency care in many low resource countries.

Our findings highlight multiple strategic actions to address problem definition, lack of credible data and positioning. Regarding problem definition, the network needs to agree on the scope and find the right balance of depth and breadth of emergency care with greater public health impact. Precise definitions of what emergency care is, who an emergency care practitioner is and what interventions are essential. Similarly, more focus needs to be placed on studying epidemiology, economic value and outcomes of emergency care and ECS. ${ }^{2324}$ The data also need to be country specific to make it relevant to local leaders, funders, policymakers and ministries of finance. ${ }^{63244}$

In summary, among the many vertical programmes competing for global health resources, the horizontal and hard-to-define nature of emergency care makes advocacy difficult. Nevertheless, the global emergency care network has had some success in gaining political attention and more can be achieved through a better definition of emergency care, developing robust evidence for effectiveness, smart framing of the issue in the broader global health context and further expanding the membership of the network beyond emergency physicians.

Furthermore, the ongoing COVID-19 pandemic has brought to light other challenges and opportunities that affects the future of global emergency care. For instance, studies in HICs report a significant decline in visits to the emergency room, even for life-threatening non-communicable diseases such as strokes and cardiac events. ${ }^{456}$ This decline has been attributed to a variety of factors including general fear of contracting COVID-19 as well as public health messaging aimed at reducing further strain to the healthcare system. ${ }^{45}{ }^{46}$ Unfortunately, the decline in healthcare-seeking behaviour disproportionately affects vulnerable populations who use the emergency room as their main entry way into the health system. In LMICs where resources are even more strained, decrease in health-seeking behaviour could lead to people presenting later in the course of the diseases process, further requiring more costly interventions. Recent literature in emergency care emphasises that a systematic approach to emergency care grounded on efficient screening, triage, stabilisation and referral can help with curbing the effects of COVID-19, improve infection control as well as allow for continuation of care for other acute non-communicable diseases.$^{474}$

Telemedicine has become an active area of focus for screening and triaging COVID-19 infection as well as for continual provision of other healthcare needs in HICs. ${ }^{45}{ }^{49}$ Recent literature highlights the potential gains in leveraging telemedicine approaches to build new tools for health system activation, field to facility communication, teletriage and telescreening, which are essential in building emergency care capacity in LMICs. ${ }^{47-49}$

The COVID-19 pandemic has highlighted the importance of an ECS as a platform to manage sudden increase in demand for healthcare. ${ }^{47} 48$ Many healthcare systems had to re-envision their surge capacity measures at the peak of the pandemic, mostly through diverting essential resources to emergency departments. ${ }^{50} 51$ The resources required included trained personnel, critical care infrastructure, medical equipment such as ventilators as well as personal protective equipment for healthcare workers. ${ }^{51}$ There has been a lot of activity in advocating for procuring such resources for LMICs. However, some leaders in the field of global emergency care caution this focus on immediate needs and highlight the importance of looking broadly at building stronger ECSs that can manage any future surge in demand. ${ }^{47}$

Twitter Junaid Abdul Razzak @JunaidRazzakMD

Contributors JAR developed the research idea, recruited participants and revised the drafts. PIC undertook interviews, literature review, analysed the data and wrote the paper. JS, YRS informed the methodology and provided input on the drafts. All authors have seen and approved the final version of this manuscript for publication. JAR isresponsible for the overall content and accepts full responsibility for the work as the guarantor. 
Funding The Johns Hopkins Department of Emergency Medicine, Focused Advanced Specialty Training program provided funding for this study. The funds were used for hiring professional transcription services.

Competing interests None declared.

Patient consent for publication Not applicable.

Ethics approval This study involves human participants but Johns Hopkins University School of MedicineReference number: IRB00204146 exempted this study Participants gave informed consent to participate in the study before taking part.

Provenance and peer review Not commissioned; externally peer reviewed.

Data availability statement Data sharing not applicable as no datasets generated and/or analysed for this study. Data are available upon reasonable request. Due to the confidentiality of the interviews, transcripts are not publicly available. However, the supplementary material provides the search strategy for the literature review and the template questionnaire used for the interviews.

Supplemental material This content has been supplied by the author(s). It has not been vetted by BMJ Publishing Group Limited (BMJ) and may not have been peer-reviewed. Any opinions or recommendations discussed are solely those of the author(s) and are not endorsed by BMJ. BMJ disclaims all liability and responsibility arising from any reliance placed on the content. Where the content includes any translated material, BMJ does not warrant the accuracy and reliability of the translations (including but not limited to local regulations, clinical guidelines, terminology, drug names and drug dosages), and is not responsible for any error and/or omissions arising from translation and adaptation or otherwise.

Open access This is an open access article distributed in accordance with the Creative Commons Attribution Non Commercial (CC BY-NC 4.0) license, which permits others to distribute, remix, adapt, build upon this work non-commercially, and license their derivative works on different terms, provided the original work is properly cited, appropriate credit is given, any changes made indicated, and the use is non-commercial. See: http://creativecommons.org/licenses/by-nc/4.0/.

\section{REFERENCES}

1 Teri R, Hendry S, Andres R. Disease Control Priorities (ThirdEdition). In: Jamison DT, Gelband H, Horton S, et al, eds. Disease control priorities: improving health and reducing poverty. 3rd Edition. Washington DC: The World Bank, 2018: 9. 247-63.

2 Razzak J, Beecroft B, Brown J, et al. Emergency care research as a global health priority: key scientific opportunities and challenges. BMJ Glob Health 2019;4:e001486-6.

3 Risko N, Chandra A, Burkholder TW, et al. Advancing research on the economic value of emergency care. BMJ Glob Health 2019;4:e001768-6.

4 Shanahan T, Risko N, Razzak J, et al. Aligning emergency care with global health priorities. Int J Emerg Med 2018;11:52.

5 Hsia RY, Thind A, Zakariah A, et al. Prehospital and emergency care: updates from the disease control priorities, version 3. World J Surg 2015;39:2161-7.

6 Razzak J, Usmani MF, Bhutta ZA, Global BZA. Global, regional and national burden of emergency medical diseases using specific emergency disease indicators: analysis of the 2015 global burden of disease study. BMJ Glob Health 2019;4:e000733-9.

7 Anderson $\mathrm{P}$, Petrino R, Halpern $\mathrm{P}$, et al. The globalization of emergency medicine and its importance for public health. Bull World Health Organ 2006;84:835-8.

8 Chowa EP, Espinola JA, Sullivan AF. Les capacités des services d'urgence au Royaume du Swaziland, Afrique. African J Emerg Med 2017;7:15-18.

9 Pandey NR. Emergency medicine in Nepal: present practice and direction for future. Int J Emerg Med 2016;9:20.

10 Anderson PD, Suter RE, Mulligan T, et al. World health assembly resolution 60.22 and its importance as a health care policy tool for improving emergency care access and availability globally. Ann Emerg Med 2012:60:35-44.

11 Hammerstedt $\mathrm{H}$, Maling S, Kasyaba R, et al. Addressing World health assembly resolution 60.22: a pilot project to create access to acute care services in Uganda. Ann Emerg Med 2014;64:461-8.

12 Sambo BH, Reynolds TA. Bulletin of the World Health Organization Ethiopia's quest to champion emergency care systems, 2020: 9-11.

13 Yiadom MYAB, McWade CM, Awoonor-Williams K, et al. Public Health Rationale for Investments in Emergency Medicine in Developing Countries - Ghana as a Case Study. J Emerg Med 2018;55:537-43.
14 Morris SC. Emergency medicine and global health policy: history and next steps. J Glob Health 2016;6:1-4.

15 Carlson LC, Reynolds TA, Wallis LA, et al. Reconceptualizing the role of emergency care in the context of global healthcare delivery. Health Policy Plan 2019;34:78-82.

16 Sriram V, Hyder AA, Bennett S. The making of a new medical specialty: a policy analysis of the development of emergency medicine in India. Int J Health Policy Manag 2018;7:993-1006.

17 Shiffman J, Schmitz HP, Berlan D, et al. The emergence and effectiveness of global health networks: findings and future research. Health Policy Plan 2016;31 Suppl 1:i110-23.

18 Shawar YR, Shiffman J, Spiegel DA. Generation of political priority for global surgery: a qualitative policy analysis. Lancet Glob Health 2015;3:e487-95.

19 Shiffman J. Four challenges that global health networks face. Int J Health Policy Manag 2017;6:183-9.

20 Shawar YR, Shiffman J. Generating global priority for addressing rheumatic heart disease: a qualitative policy analysis. J Am Heart Assoc 2020;9:e014800.

21 Schatz E. Political ethnography. Chicago: University of Chicago press, 2009.

22 Tong A, Sainsbury P, Craig J. Consolidated criteria for reporting qualitative research (COREQ): a 32-item checklist for interviews and focus groups. Int J Qual Health Care 2007;19:349-57.

23 Calvello EJB, Tenner AG, Broccoli MC, et al. Operationalising emergency care delivery in sub-Saharan Africa: consensusbased recommendations for healthcare facilities. Emerg Med $J$ 2016;33:573-80.

24 Moresky RT, Razzak J, Reynolds T, et al. Advancing research on emergency care systems in low-income and middle-income countries: ensuring high-quality care delivery systems. BMJ Glob Health 2019;4:e001265-8.

25 Smith J, Haile-Mariam T. Priorities in global emergency medicine development. Emerg Med Clin North Am 2005;23:11-29.

26 Razzak JA, Kellermann AL. Emergency medical care in developing countries: is it worthwhile? Bull World Health Organ 2002;80:900-5.

27 Mould-Millman N-K, Dixon J, Lamp A, et al. A single-site pilot implementation of a novel trauma training program for prehospital providers in a resource-limited setting. Pilot Feasibility Stud 2019;5:1-13

28 Arreola-Risa C, Vargas J, Contreras I, et al. Effect of emergency medical technician certification for all prehospital personnel in a Latin American City. J Trauma - Inj Infect Crit Care 2007;63:914-9.

29 Merchant A, Outhay M, Gonzaléz-Calvo L, et al. Training laypersons and hospital personnel in basic resuscitation techniques: an approach to impact the global trauma burden in Mozambique. World J Surg 2015;39:1433-7.

30 Ramos P, Paiva JA. Dedication increases productivity: an analysis of the implementation of a dedicated medical team in the emergency department. Int J Emerg Med 2017;10:8

31 Burkholder TW, Hill K, Calvello EJ. Developing emergency care approach, 2020: 1-13.

32 Hsia R, Razzak J, Tsai AC, et al. Placing emergency care on the global agenda. Ann Emerg Med 2010;56:142-9.

33 Phillips GA, Soe ZW, Kong JHB, et al. Capacity building for emergency care: training the first emergency specialists in Myanmar Emerg Med Australas 2014;26:618-26.

34 Phillips GA, Hendrie J, Atua V, et al. Capacity building in emergency care: an example from Madang, Papua New Guinea. Emerg Med Australas 2012:24:547-52

35 Busse H, Azazh A, Teklu S, et al. Creating change through collaboration: a twinning partnership to strengthen emergency medicine at Addis Ababa University/Tikur Anbessa Specialized Hospital--a model for international medical education partnerships. Acad Emerg Med 2013;20:1310-8.

36 Rominski SD, Yakubu J, Oteng RA, et al. The role of short-term volunteers in a global health capacity building effort: the project HOPE-GEMC experience. Int J Emerg Med 2015;8:6-10.

37 Anthony DR. Promoting emergency medical care systems in the developing world: weighing the costs. Glob Public Health 2011;6:906-13.

38 Jahn HK, Kwan J, O'Reilly G, et al. Towards developing a consensus assessment framework for global emergency medicine fellowships. BMC Emerg Med 2019;19:68.

39 Adeloye D. Prehospital trauma care systems: potential role toward reducing morbidities and mortalities from road traffic injuries in Nigeria. Prehosp Disaster Med 2012;27:536-42.

40 O'Reilly GM, Gabbe B, Braaf S, et al. An interview of trauma registry custodians to determine lessons learnt. Injury 2016;47:116-24.

41 Patel S, Koku Awoonor-Williams J, Asuru R, et al. Benefits and limitations of a Community-Engaged emergency referral system in 
a remote, impoverished setting of northern Ghana. Glob Health Sci Pract 2016;4:552-67.

42 Ndile ML, Saveman B-I, Outwater AH, et al. Implementing a layperson post-crash first aid training programme in Tanzania: a qualitative study of stakeholder perspectives. BMC Public Health 2020;20:1-7.

43 Shawar YR, Shiffman J. Generation of global political priority for early childhood development: the challenges of framing and governance. Lancet 2017;389:119-24.

44 Sun JH, Twomey M, Tran J, et al. The need for a usable assessment tool to analyse the efficacy of emergency care systems in developing countries: proposal to use the TEWS methodology. Emerg Med $J$ 2012;29:882-6.

45 Hartnett KP, Kite-Powell A. Impact of the COVID-19 pandemic on emergency department visits - United States, January 1 2019-May 30,2020 . us. Department of health and human Services/Centers for disease control and prevention. MMWR 2020;69:699-704.

46 Jeffery MM, D'Onofrio G, Paek H, et al. Trends in emergency department visits and hospital admissions in health care systems in 5 states in the first months of the COVID-19 pandemic in the US JAMA Intern Med 2020;180:1328-33.

47 Emergency care in the pandemic. Bull World Health Organ 2020;98:650-1.

48 Mowafi H, Sakr H, Ravaghi H, et al. Leveraging the COVID-19 response to improve emergency care systems in the eastern Mediterranean region. East Mediterr Health J 2020;26:626-9.

49 Ohannessian R, Duong TA, Odone A. Global telemedicine implementation and integration within health systems to fight the COVID-19 pandemic: a call to action. JMIR Public Health Surveill 2020;6:e18810.

50 Jachetti A, Colombo G, Brignolo-Ottolini B, et al. Emergency department reorganisation to cope with COVID-19 outbreak in Milan university hospital: a time-sensitive challenge. BMC Emerg Med $2021 ; 21: 74$

51 Uppal A, Silvestri DM, Siegler M, et al. Critical care and emergency department response at the epicenter of the COVID-19 pandemic. Health Aff 2020;39:1443-9. 